\title{
Use of Porous Titanium Trabecular as a Bone Defect Regenerator: In Vivo Study
}

\author{
Ana Isabel Torres Pérez ${ }^{1, *}$, Mariano Fernández Fairén ${ }^{2}$, Ángel Antonio Torres Pérez ${ }^{3}$ and Javier Gil Mur ${ }^{4, *(1)}$ \\ 1 Department Cirugia Ortopédica y Traumatología, Facultad de Fisioteripa y Medicina, \\ Hospital Universitario Santa Lucia, Universidad Católica de Murcia, c/Mezquita s/n, Paraje los Arcos, \\ 30202 Cartagena, Spain \\ 2 Bioengineering Institute of Technology, Universitat Internacional de Catalunya, c/Josep Trueta s/n, \\ Sant Cugat del Vallés, 08195 Barcelona, Spain; mferfai@gmail.com \\ 3 Technology Department, University of Northampton, Waterside Campus, University Drive, \\ Northampton NN1 5PH, UK; angeltp@gmail.com \\ 4 Facultad de Odontología, Universitat Internacional de Catalunya, c/Josep Trueta s/n, Sant Cugat del Vallés, \\ 08195 Barcelona, Spain \\ * Correspondence: anatpz@gmail.com (A.I.T.P.); xavier.gil@uic.es (J.G.M.)
}

check for updates

Citation: Torres Pérez, A.I.; Fernández Fairén, M.; Torres Pérez, Á.A.; Gil Mur, J. Use of Porous Titanium Trabecular as a Bone Defect Regenerator: In Vivo Study. Metals 2022, 12, 327. https://doi.org/ $10.3390 /$ met12020327

Academic Editor: Ling Ren

Received: 30 December 2021

Accepted: 8 February 2022

Published: 12 February 2022

Publisher's Note: MDPI stays neutral with regard to jurisdictional claims in published maps and institutional affiliations.

Copyright: (C) 2022 by the authors. Licensee MDPI, Basel, Switzerland. This article is an open access article distributed under the terms and conditions of the Creative Commons Attribution (CC BY) license (https:// creativecommons.org/licenses/by/ $4.0 /)$.

\begin{abstract}
The application of porous materials is increasingly being used in orthopaedic surgery due to its good results. Bone growth within the pores results in excellent mechanical fixation with the bone, as well as good bone regeneration. The pores, in addition to being colonised by bone, produce a decrease in the modulus of elasticity that favours the transfer of loads to the bone. This research shows the results of an experimental study where we have created critical osteoperiosteal defects of $10 \mathrm{~mm}$ on rabbit's radius diaphysis. In one group of 10 rabbits (experimental group) we have implanted a bioactive porous titanium cylinder, and in another group we have allowed spontaneous regeneration (control group). Mechanical tests were performed to assess the material. Image diagnostic techniques (X-ray, scanner and 3D scan: there are no references on the literature with the use of CT-scan in bone defects) and histological and histomorphometric studies post-op and after 3, 6 and 12 months after the surgery were performed. All the control cases went through a pseudoarthrosis. In 9 of the 10 cases of the experimental group complete regeneration was observed, with a normal cortical-marrow structure established at 6 months, similar to normal bone. Titanium trabecular reached a bone percentage of bone inside the implant of $49.3 \%$ on its surface 3 months post-op, $75.6 \%$ at 6 months and $81.3 \%$ at 12 months. This porous titanium biomaterial has appropriate characteristics to allow bone ingrowth, and it can be proposed as a bone graft substitute to regenerate bone defects, as a scaffold, or as a coating to achieve implant osteointegration.
\end{abstract}

Keywords: porous titanium; bone regeneration; CT-SCAN; osseointegration

\section{Introduction}

The treatment of bone defects represents an unsolved problem in reconstructive orthopaedic surgery, and the most frequent procedures used on the treatment of those defects are the bone grafts. Each previous procedure presents its proper advantages and disadvantages. The use of autologous bone graft can produce morbidity on the donor site and patient discomfort as the quantity of bone obtained was limited. Fresh or frozen bone allografts present antigenicity problems and low biological activity, which reduces their integration.

Cellular metallic prosthesis presents a particular interest in orthopedics applications, due to the reduction of the stiffness between bone tissues and titanium implants avoiding the stress shielding. This stiffness can be controlled by adjusting the pore size and total porosity of the implant. These aspects favor the replacement of damaged or broken bones [1-4]. Abate et al. [5] studied the design and optimization of the hip implant by 
introducing a cellular structure into a solid implant to allow bone tissue in growth and reduce stress shielding. The cellular hip implant is incorporated with vintiles lattice topologies with different strut thickness and unit cell sizes to achieve the requirements of bone ingrowth and biomechanical mimic strength. The cellular hip implants with different unit cell size and porosity were manufactured via selective laser melting (SLM) using the Ti6Al4V material. The result of this study showed that the cellular implants with porosity of $56 \%$ and $58 \%$ have the potential to be used in orthopedic and prosthetic applications to improve osseointegration.

Dense metallic biomaterials represent only an interfacial connection with host tissue, and as it has mentioned, develop stress shielding, which causes ingrowth of the fibrous tissue, and are also prone to microbial adhesion and the development of biomaterialassociated infections [6]. Therefore, development of porous titanium biomaterial is necessary to improve an implant's interconnection with bone, provide better stabilization, and reduce the risk of the loss of the implant. Substantial pore interconnectivity in metallic implants should allow extensive body fluid transport through the porous implant. This can provoke bone tissue ingrowth, consequently leading to the development of highly porous metallic implants, which could be used as scaffolds in bone tissue engineering [7].

Several simulations by finite element analysis (FEA) were carried out, with validation of the cellular implants testing under static loading conditions having been studied in order to optimize the designs [8,9]. Abate et al. [10] showed an acetabular cup (AC) with cellular structure showing an internal porosity of $56-87.9 \%$, and internal pore dimensions in the range of 600-1200 $\mu \mathrm{m}$. The AC implant was then optimized for improving mechanical performance to reduce stress shielding by adjusting the porosity to produce stiffness (elastic modulus) to match with the bone, and allowing for bone cell ingrowth $69 \%$. In addition, new metals such as tantalum have been introduced in an effort to enhance osseointegration potential of uncemented components. In order to encourage and enhance the bonding of these porous metallic components to bone, various bioactive coatings such as hydroxyapatite (HA) have been developed [11-14]. These bioactive materials degrade over time, and have the potential to bond from the underlying metallic surface [15]. Tantalum also offers a low modulus of elasticity, high surface frictional characteristics, high porosity $(80 \%)$ and excellent osseointegration properties (i.e., bioactivity, biocompatibility and ingrowth properties) [16,17]. However, long-term follow-up is not yet available, and the higher cost of this material has limited its widespread use $[18,19]$.

In addition to the different designs, materials and manufacturing methods are studied to achieve all kinds of shapes with complicated geometries with good mechanical properties and cellular structures with porosity levels that can be controlled [20]. All these advances enable the field of porous structures to produce very important advances in orthopedic surgery and traumatology.

Based on the clinical outcomes and histological evidence from retrieved porous implants, it is clear that porous surfaces support tissue ingrowth or ongrowth, and are generally effective for supplementing the stability of the implant by biological fixation, but classical porous materials have weaknesses. New porous trabecular titanium materials have a high and interconnecting porosity with a regular pore shape and size, and are stiffer than the classical ones. We have proposed the following work hypothesis: new porous trabecular titanium can be used to obtain bone regeneration in critical bone defects.

To simplify the study, we have stablished the following aims:

1. Make a mechanical study of this porous titanium implant

2. Evaluate and compare bone regeneration in both groups (experimental and control) with image diagnosed techniques (simple x-ray, scanner) and morphodensitometric analysis

3. Evaluate the bone regeneration in both groups with histologic techniques: optical microscopy, transmission and scanning electron microscopy and morphodensitometric analysis 


\section{Materials and Methods}

Porous titanium scaffold was produced by Powder Metallurgy (PM) technique mixing commercially pure titanium, with a mean grain size of about $80 \mu \mathrm{m}$, with $\mathrm{NaCl}$ particles of 300 to $600 \mu \mathrm{m}$ of diameter as space holder, in a 65 -to- $35 \%$ volume ratio. In order to homogenize the mixture, ethylene glycol $(15 \mathrm{wt} \%)$ was added as a binder phase and removed at $200{ }^{\circ} \mathrm{C}$ in air.

The mixture was uniaxially pressed under $100 \mathrm{MPa}$ in a stainless steel mold, and then isostatically pressed under $200 \mathrm{MPa}$. The space holder was removed by washing samples several times with distilled water until conductivity remained stable. Sintering of porous titanium was carried out at $1350{ }^{\circ} \mathrm{C}$ during $2 \mathrm{~h}$ under high vacuum conditions at $5 \times 10^{-4}$ mbar. The affinity of titanium for oxygen is very high, and its incorporation can affect mechanical properties in a very important way. Therefore, high resolution microanalysis (Perkin-Elmer Physical Electronics, Waltham, MA, USA) studies were carried out to determine whether the sintering process has contaminated the titanium with oxygen. The results showed that there were no differences in titanium before and after treatment; this fact ensures the good quality of the treatment. Characterization of micro- and macroporosity (pore diameters greater than $10 \mu \mathrm{m}$ ) was done by mercury immersion porosimetry using AutoPore IV 9500 V1.07 equipment (MIP, Micrometrics, Norcross, GA, USA).

Mechanical properties were evaluated by means of servohydrualic test machine special for the biomaterials with load cells from $1 \mathrm{~g}$ to $1000 \mathrm{~kg}$, (MTS Bionix 370 (MTS, Eden Prairie, MN, USA)) for the Titanium porous structures. The tests were performed in compression, tensile, torsion and flexural at three points according to the ASTM standards. Fatigue tests were performed in compression-compression mode, using frequencies of $15 \mathrm{~Hz}$ and $37^{\circ} \mathrm{C}$ in physiological medium with a maximum of cycles of $6 \times 10^{6}$ determining the fatigue limit strength.

The samples were trabecular titanium cylinders sterilised under gamma radiation with $20 \mathrm{~mm}$ long and $5 \mathrm{~mm}$ of diameter commercially pure Titanium (c.p.-Ti) grade 3. We wanted to check that trabecular titanium presented all the characteristics of stability demanded to be employed as scaffold in osseoregeneration, and could be employed to validate our hypothesis.

An in-vivo study was carried out in eighteen female adult New Zealand White (NZW) rabbits (Charles River, Saint Aubin les Elboeuf, France), aged six months with an average body weight of $5 \mathrm{~kg}$ (range 4-6 kg). Tests were prospective, randomized and blind evaluation (the radiologist did not know the time of the follow-up of the rabbit before death; they just received the arm of the rabbits with a code of the side), in order to evaluate the bone regeneration obtained in critical bone defects of $10 \mathrm{~mm}$ length done on the medial part of radius rabbit diaphysis. The study was conducted in accordance with the Declaration of Helsinki, and the protocol was approved by the Research Ethical Committee of the Facultad de Veterinaria of the Universidad Autónoma de Barcelona with reference UAB-CEA AH2016, and conducted according to the European Community guidelines for the care and use of laboratory animals (DE 86/609/CEE).

We have chosen this size of sample, situation and bone defect following the same directions employed on the scientific literature about bone regeneration in rabbit bone.

Under standard aseptic surgical techniques, in one of the limbs a titanium trabecular bar was implanted between the defect extremes (osseoconductive function) and fixed on the marrow conducts (stabilized function-Figure 1). No implant was placed on the contralateral limb to see spontaneous evolution.

Bone regeneration obtained was evaluated and compared between groups employing monthly X-rays taken during one year, including CT-scan and morphometric quantification and densitometry studies.

All the rabbits operated on, with or without implants, were placed on the same conditions of weight bearing on the limbs (they were allowed to walk freely in their cages). A period of one month was stablished between the surgery of one limb and the contralateral (to allow the complete healing of the animal). 

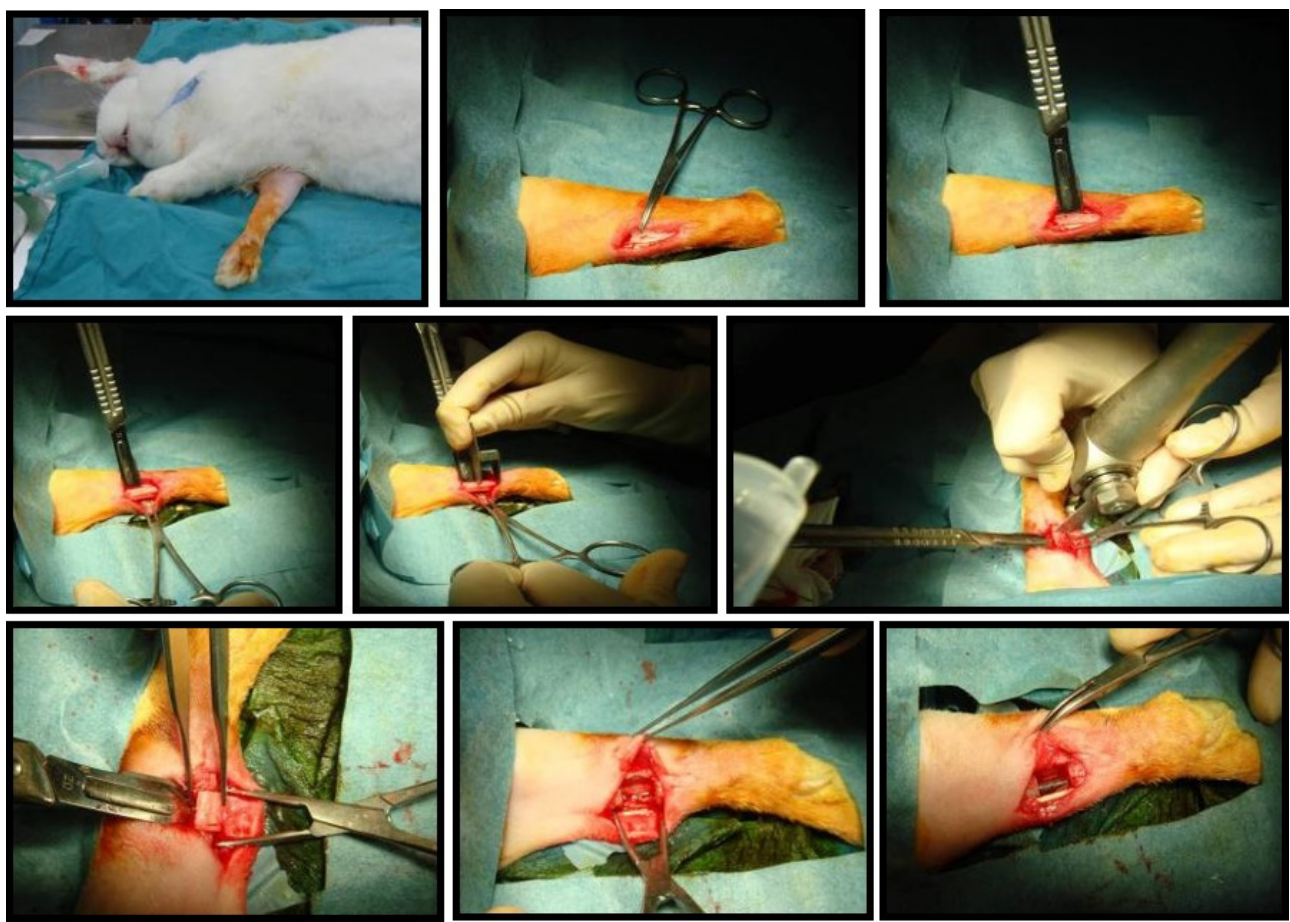

Figure 1. Surgical technique.

Our goal was to obtain monthly radiographic results during a year of follow-up, and to have at least 3 months of follow-up for each rabbit. We have made the following plans to distribute the dates of surgery and follow-up: 2 legs ( 1 with and 1 other without trabecular titanium (TT)) and 12 months of FUP; 8 legs (4 with and 4 other without TT) and 6 months of FUP; and 10 legs ( 5 with and 5 other without TT) and 3 months of FUP.

After surgery, the animals were under veterinary supervision and allowed to recover without limitation of diet or activity with standard conditions of temperature, humidity, ventilation, noise and circadian rhythm light-dark. In all the animals' pre-operatory stage, X-rays were taken (to verify the physis fusion) immediately post-op, and monthly for 6 months, 9 and 12 months (depending on the animal), both before and after the euthanasia. A radiological retro-alveolar unit (Throphy 708-CCX-Digital), dental radiographical films Kodak Ultra Speed ${ }^{\mathrm{TM}}$ and a team developing of the X-ray films were owned by the University of Oviedo. Bone regeneration type was evaluated by a qualitative ordinal scale of complete, partial or none, and a temporary sequence analysis was used for the bone regeneration.

Two types of quantification radiographic digitalized image studies (radiological optometry) were done: morphometric (radiological optomorphometry); and densitometry (radiological optodensitometry).

ImageJ $\mathrm{v} 1.44^{\circledR}$. was the program employed to obtain the measures of optical and morphological densities.

The parameters of radiological quantification studied were: the percentage of bone regenerated on the defect; and the density of the bone regenerated on the defect.

The legs obtained after the euthanasia were studied under a CT-scan performing a CT-scan helicoidally and 3D reconstruction to evaluate restitution or not of the bone continuity of the radius. A densitometry study performed with a General Electric Helicoidally Hi-Speed ${ }^{\circledR}$ team was done on the rabbit's legs of both groups with and without TT. Densitometry quantification, in Hounsfield units, of the regenerated bone on the defect and healthy bone was blindly done in axial cuts by the radiologist.

The parameters studied on the densitometry quantification by CT-scan were: healthy bone density; regenerated bone density; and density recovered. 
At last, bone regeneration in both groups was evaluated with histological techniques (optical microscopy, transmission and scanning electron microscopy) and studies of histomorphometric quantification. Histological preparation included dehydrating, defatting and embedding in acrylic. The implants were sectioned transversely. Once the pieces were prepared, they have been studied under the optical microscopy and pictured with a digital camera (DP12 ${ }^{\circledR}$, Olympus, Tokyo, Japan) and the acquisition image system $\left(\mathrm{PCTV}^{\circledR}\right.$, Pinnacle Systems, Mountain View, CA, USA).

Through microscopy, the anatomopathologist blindly studied the following parameters: existence of interposition tissue between the bone regenerated and the TT; existence of bone on the TT bar; and percentage of the implant perimeter surrounded by bone. The parameters measured histomorphometrically were: implant percentage in direct contact with bone (\% bone-implant); and percentage of bone in the implant.

An ultrastructural study was done through transmission electron microscopy (Zeiss EM-109 $\left.{ }^{\circledR}\right)$, and on the micropictures, the bone growth inside the porous implant was studied, measuring the percentage of regenerated bone in the implant.

Under scanning electron microscopy (JSM $6400^{\circledR}$, Jeol, Japan), the interface between the bioactive implant and the bone was seen, checking how the regenerating bone covered the implant surface.

All the values were registered and analyzed through the statistical program SPSS ${ }^{\circledR}$ 17.0. Significance value elected was $95 \%(p<0.05)$.

\section{Results}

Interconnected porosity of the scaffolds was of 53\%, with macropores of $210 \mu \mathrm{m}$ of diameter on average and interconnectivity of $57 \mu \mathrm{m}$ [21]. Figure 2 shows the porous titanium obtained.

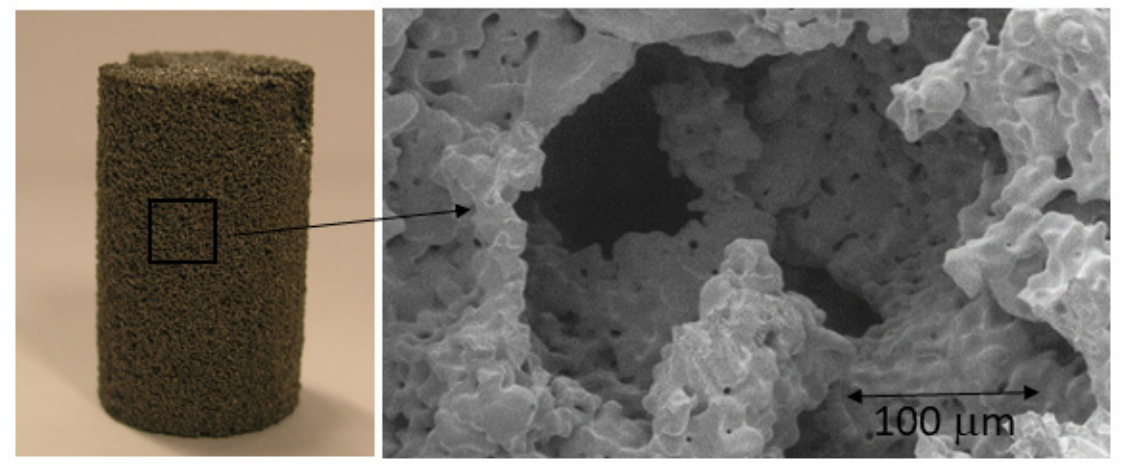

Figure 2. Porous titanium obtained by PM.

Our Ti porous implants showed adequate mechanical properties and a Young's modulus close to that of the cancellous bone. Trabecular titanium starts being deformed around $70 \mathrm{MPa}$, and it resists without the appearance of macroscopic cracks until $250 \mathrm{MPa}$, with $5 \mathrm{~mm}$ of displacement. Increasing the movement, the plastic deformity of the implant starts once the first crack appears, and the flexion resistance is reduced faster. The first crack appeared at $8 \mathrm{~mm}$, under strength of $60 \mathrm{MPa}$.

TT resists better perpendicular transmission forces, and worst the axial ones (Table 1). Its resistance is upper $60 \mathrm{MPa}$ under compression, and around $60 \mathrm{MPa}$ for static flexion (Table 1). The highest resistance of trabecular titanium appears under static compression strength (Table 1).

TT demonstrated to be very water permeable (it is titanium foam with an open pore structure).

TT breaks for fatigue after six million cycles under a contact pressure of $50 \pm 11 \mathrm{MPa}$.

Through the results obtained on the mechanical test, we have seen that trabecular titanium is a material with similar mechanical properties compared to bone, and which presented all the requirements to be employed in our study. 
Table 1. Results after compression, flexion, tension, torsion and cyclic compression test.

\begin{tabular}{cccc}
\hline Mechanical Tests & $\begin{array}{c}\text { Elastic Modulus } \\
(\mathbf{G P a})\end{array}$ & Yield Strength (MPa) & Maximal Strength (MPa) \\
\hline Compression & $\mathrm{K}=9.0 \pm 0.9$ & $67.7 \pm 3.5$ & $249 \pm 15$ \\
\hline Flexion & $\mathrm{E}=7.6 \pm 0.5$ & $61.5 \pm 3.9$ & $105 \pm 20$ \\
\hline Tension & $\mathrm{E}=13.6 \pm 1.7$ & $63.1 \pm 2.5$ & $70 \pm 11$ \\
\hline Torsion & $\mathrm{G}=7.7 \pm 0.4$ & $33.1 \pm 3.5$ & $62 \pm 5$ \\
\hline
\end{tabular}

Radiologically, in 9 cases of titanium trabecular group and none of the control group, the continuity of the cortical and the marrow on the bone defect was re-established after 5 months of follow-up.

At the trabecular titanium group, the immediate post-op defect bone density on the X-ray (Figure 3 ) was water. At early periods (1-2 months) follow-up, two calcium density areas were seen continuing the osteotomies borders, with a different amount of bone on the central region. 3-4 months after the surgery, the calcium density increased, creating a more defining area with higher density at the outskirts. 5-6 months later, the radiographic continuity of the radius was reached with a density similar to normal bone at the trabecular titanium group. From 9 months post-op, the density of the bone growth on the defect increased. Differences on bone regeneration at the trabecular titanium group between 6 and 9 months post-op were small.
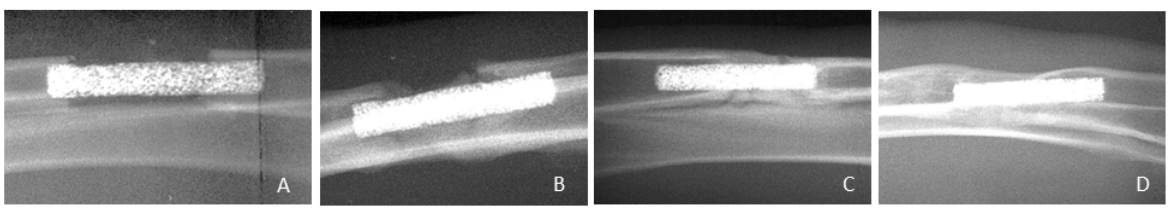

Figure 3. X-rays during the follow-up. (A) 0 months, (B) 2 months, (C) 4 months, (D) 6 months.

None of the legs from the control group reached a total or partial filling of the defect after 12 months of follow-up. There was a statistic significant association between the parameters closing of the bone defect and implantation of trabecular titanium.

From the helicoidally images of the CT-scan (Figure 4), we have obtained a 3D reconstruction where we have observed the radius complete bone continuity (in 9 legs) of the bone defect at the trabecular titanium group. On the control group, any radius showed complete regeneration at the helicoidally CT-scan, and neither on the 3D reconstruction.

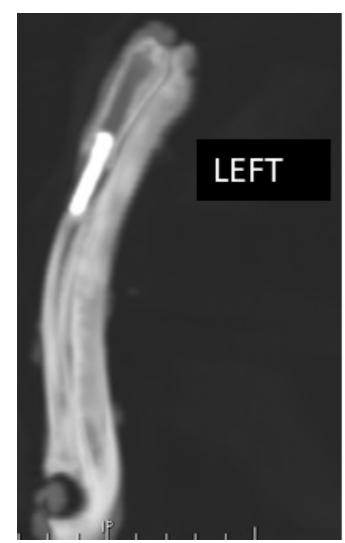

(A)

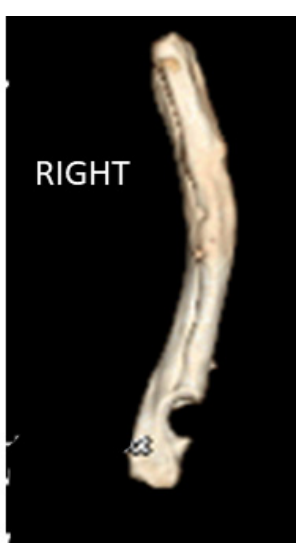

(B)

Figure 4. (A) CT-Scan helicoidally images to estimate restauration of the radius continuity. (B) 3D Reconstruction of the CT-scan helicoidally images to estimate restauration of the radius continuity. 
The parameters restitution of the radius continuity and presence of trabecular titanium were dependent and statistically significant. Statistically significant differences were seen between the groups trabecular titanium and the control for all the different periods of time post-op evaluated in this study.

The percentage of bone regeneration at the trabecular titanium group was superior than the control group for each one of the follow-up periods. The density increased, progressively stopping being significant until the 4th month at the titanium trabecular group. When the values obtained were represented (Figure 5), we have seen a continuous progression of the bone growth from implantation until 6 months' post-op, where a plateau appeared.

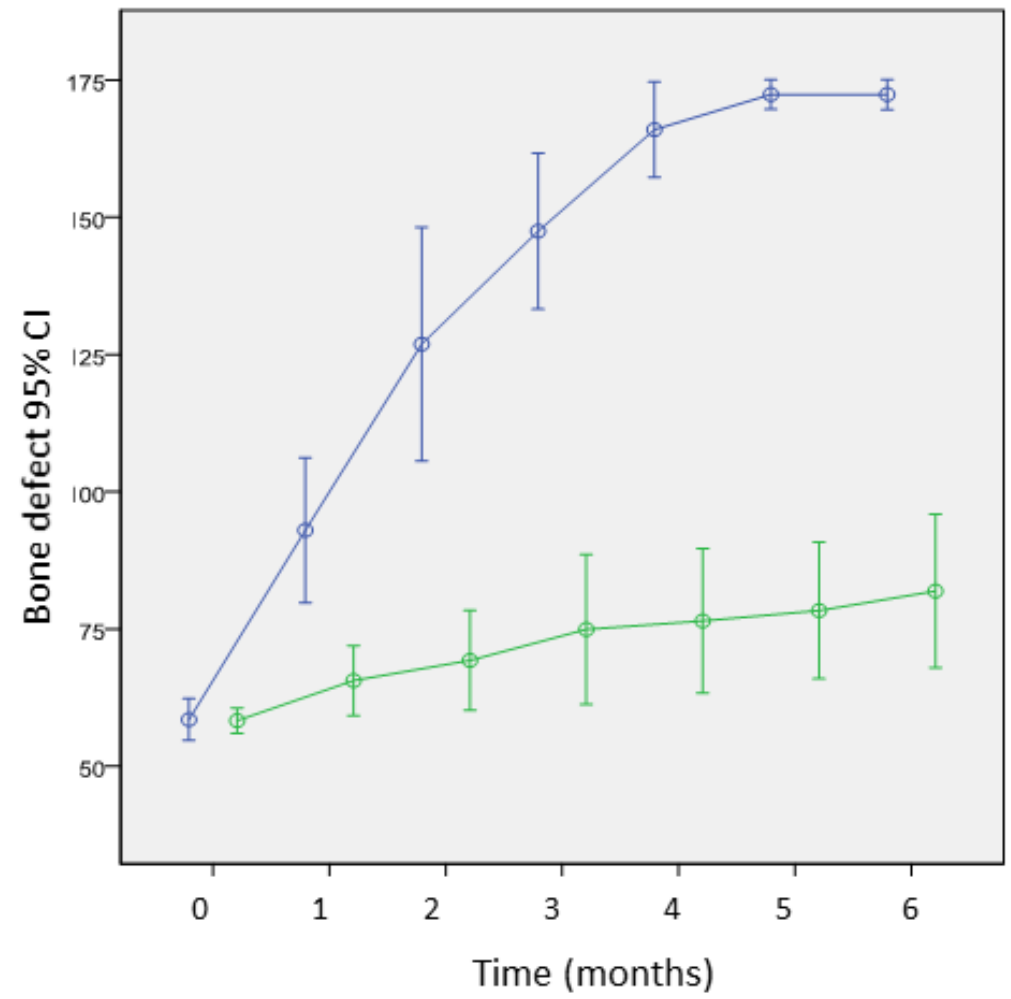

Figure 5. Defect bone growth progression in the titanium trabecular group (circles, blue) and control group (squares, green).

Concerning the densitometric quantification studies performed through CT-scan, the axial and sagital images obtained on the bone defects with titanium trabecular demonstrated a total defect bone regeneration on the X-ray, also showing a cortico-marrow pattern very similar to normal bone, although the cortical density was slightly minor.

In all the legs with titanium trabecular, the anatomopathological studies showed normal bone formation inside the defect.

3 months after the implantation, there was a considerable quantity of new bone in the group of titanium trabecular. Even one case showed $80 \%$ bone at 3 months post-op.

Optical microscopy shows a mineralized new bone with a laminar structure. At the control group, we have observed the lack of bone union between the borders of the osteotomy. Just a little amount of cortical bone was detected, and a radioulnar sinostosis made by the ossification of the interosseous membrane. The central part of the bone defect was filled with fibrous tissue, as well as muscles coming from the surrounding tissues.

At the 6-month follow-up, at the titanium trabecular group we have seen a bone pattern similar to normal bone with a cortical homogeneous layer (progressively thicker as follow-up was going on) (Figure 6). 


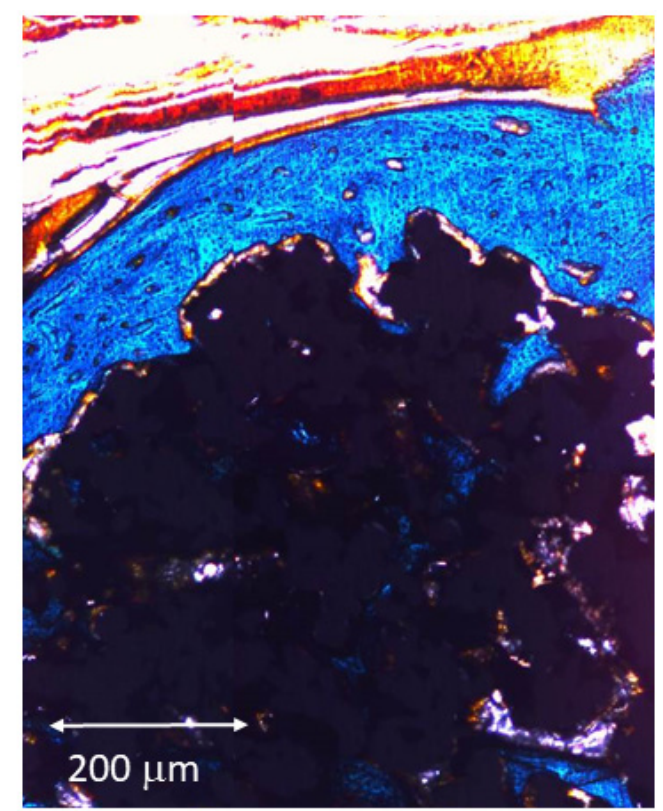

Figure 6. Cortical-marrow pattern of regenerated bone.

A direct union between regenerated bone and titanium trabecular was seen. We have even seen bone with osteons and cells that looked like viable osteocytes (Figure 7).

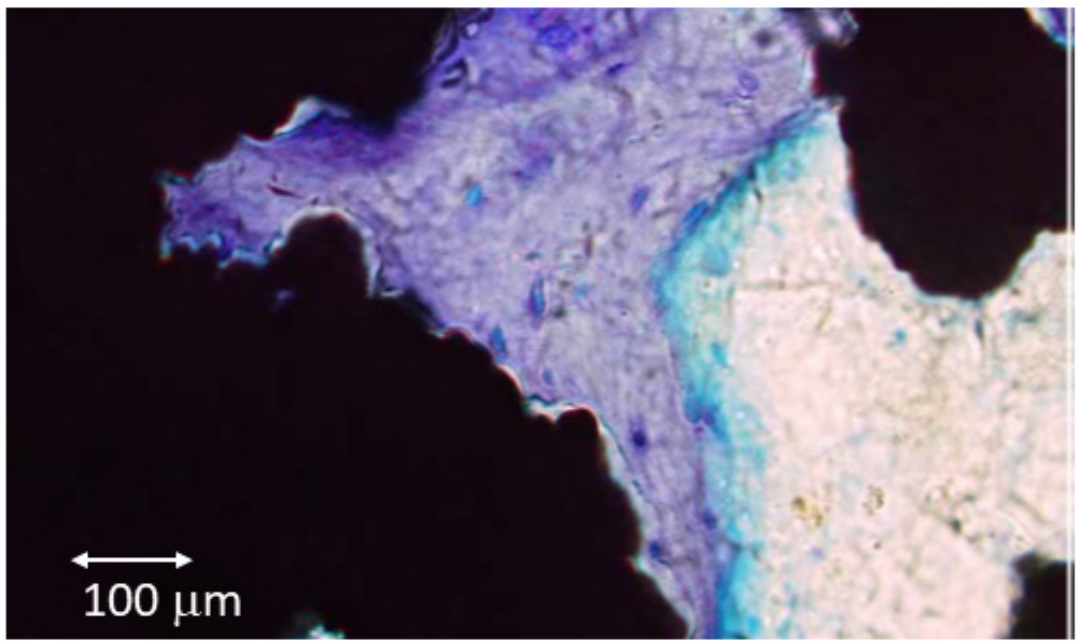

Figure 7. Normal bone structure with osteocytes inside the lacunas and canalicular mesh (Giemsa stain).

The bone percentage at the perimeter on the titanium $t$ rabecular group after 3 months post-op was superior at 75\% in all the cases. The difference between 3 and 6 months post-op was statistically significant, showing that the cortical bone density increased between those two periods of time. From the sixth month until the end of the year, the density increased slowly with a statistical significant difference of 10 points. The highest percentage of bone inside the implant was situated on its extremes.

Titanium trabecular reached a bone percentage of bone inside the implant of $49.3 \%$ on its surface 3 months post-op, as well as $75.6 \%$ at 6 months and $81.3 \%$ at 12 months.

Transmission electron microscopy showed the direct contact of the new bone and the implant surface at 3 and 6 months. Ultrastructural images of ossification in the Titanium Trabecular group structure were seen in (Figure 8). 

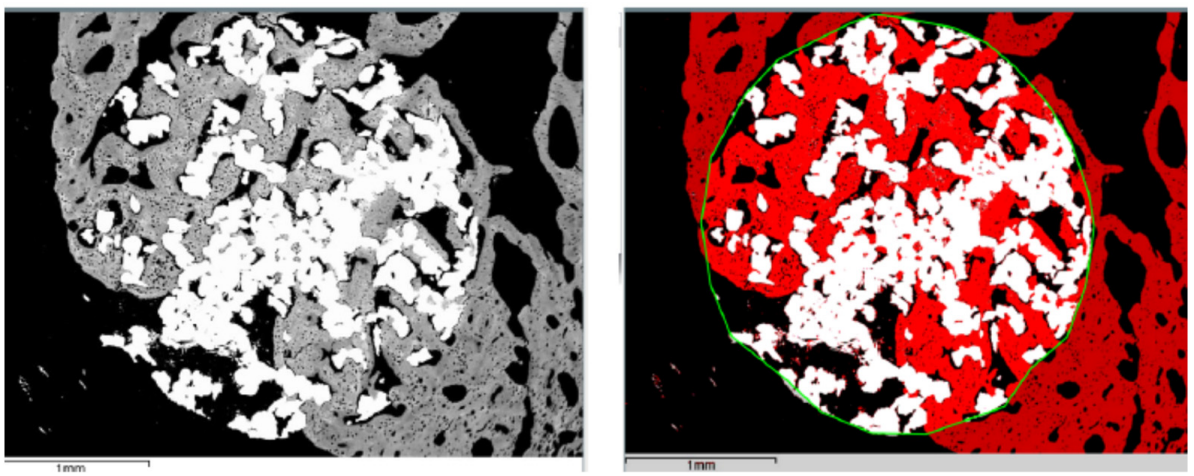

Figure 8. Transmission electron microscopy image, where mature laminar bone can be seen inside the pores of the metallic structure. Image on the left: $35 \times$. Image on the right: segmentation performed to achieve the histomorphometric study.

At 3 months, the mean bone percentage on the porous surface of the implant was $54.4 \%(53-56) \%$; while at six months it was 70. 5\% (69-72)\%; and at 12 months it was $78 \%$ (76-79).

Differences between sixth and third month post-op and sixth and 12 months post-op were statistically significant.

With scanning electron microscopy (Figure 9), we have seen direct contact between the new bone and the implant. The bone regenerated was normal bone without inflammatory cells or signs of necrosis.

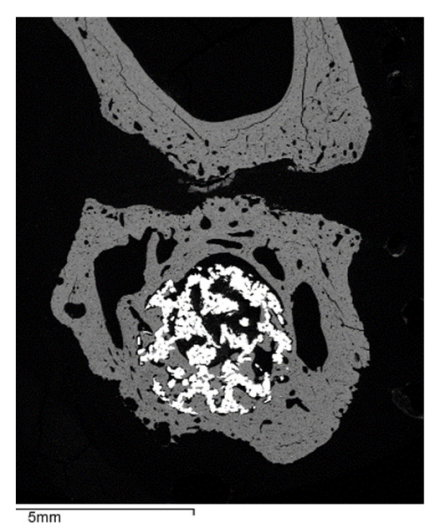

(A)

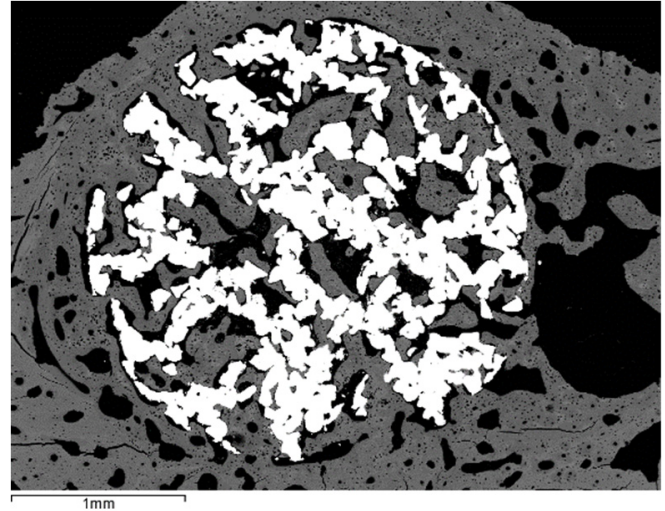

(B)

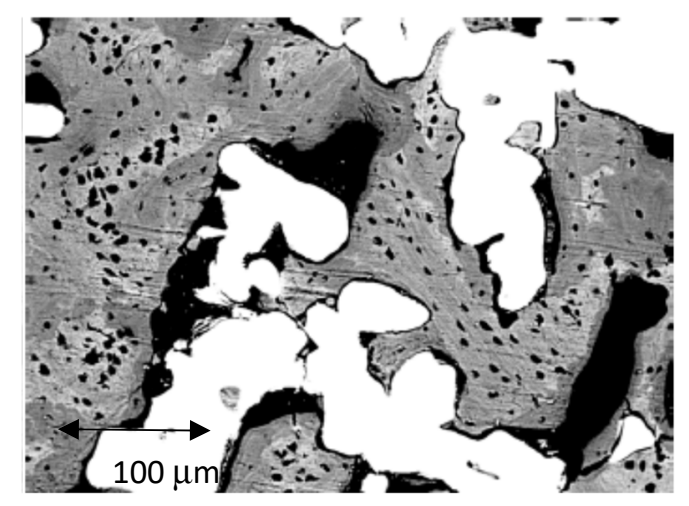

(C)

Figure 9. Scanning electron microscopy images: (A) Position on the implant inside de radius, bone integration at 3 months; (B) Bone regeneration inside and around the implant at 12 months; and (C) Direct union bone and implant. 


\section{Discussion}

Evaluating the results obtained in our mechanical studies, trabecular titanium demonstrated to be a stable and resistant material appropriate to be employed as a scaffold on the bone defect regeneration. The stiffness and resistance of titanium trabecular is situated between the cancellous and cortical bone.

The powder metallurgy process is able to produce Ti foams with adjustment of the pore size within the range required for bone ingrowth [22,23]. Implants with a pore size ranging from 50 to $40 \mu \mathrm{m}$ have been considered acceptable to allow biological anchorage and the formation of a new vascular system for continuing bone ingrowth [24-28]. In a recent study, Teixeira et al. [29] suggested that porous Titanium surfaces with pore sizes near $62 \mu \mathrm{m}$ yield the highest expression of osteoblast phenotype, as indicated by the lower cell proliferation rate and higher gene expression of bone markers.

The tridimensional micro porous structures are related with the in-vitro formation of apatite on titanium treated chemically and thermally [30]. The interconnected porous structure plays an important role in osteogenesis, and the distribution of the interpore connexion is correct to allow the cell invasion [31]. The optimal pore diameter to allow osseoconduction in vivo is situated between 150 and $500 \mu \mathrm{m}[32,33]$.

We have analyzed the quality of osseointegration after short and medium follow-up, and characterize the response of bone to a new porous titanium biomaterial in a critical bone defect.

After 12 weeks of implantation, new bone was formed in direct contact with the implant.

The obtained results with this implant, on this animal model and with this surgical technique, showed that once the $78 \%$ of the direct bone contact with the implant is reached, the growth stops. Once the amount of bone to obtain the mechanical stabilization of the implant is reached, the bone quality increases through its remodelation, and immature bone (osteoid) changes into laminar bone.

Branemark et al. [34] established a correlation between the bone quantity at the interface and the mechanical capacity of the implants. When the bone percentage increases, the value of the torque and maximum strength needs to loosen the implant.

We have seen that the immature bone growth starts with direct contact, with the implant going to the implant surface (centrifuge growth). Centrifuge growth shows an osseoinductive being of the bioactive and rough implants. Those results are similar to the ones obtained with titanium, titanium coated with hydroxyapatite [29], fluoroapatite [35] or calcium ions [36].

Titanium metal is considered a bioinert material, and is used for scaffolds when loaded with BMP to induce ectopic bone formation [37-39].

Fujibayashi et al. [40] showed that titanium metal could be converted into an osseoconductive material through specific chemical and thermal treatments.

We have verified, as authors said in [40-42], that the complex macro-porous structure of the implant plays an important role in material-induced osseogenesis and osseointegration, and have seen the good adhesion between the apatite layer growth on the titanium and the bone growth on its surroundings.

There are no references on the literature with the use of CT-scan in bone defects regeneration studies. We thought that a CT-scan could be useful to obtain additional information. From our radiological and histological results and the literature $[43,44]$, it seems that the bone defect regeneration starts from the extremes to the central part. The CT-scan study showed a cortico-marrow regenerated pattern similar to normal bone in both in the trabecular titanium group.

On the morphometric study realized with CT-scan, we have demonstrated the association between the parameters titanium trabecular and radius continuity restitution. The bone regeneration percentage on the titanium trabecular group was superior from the control group in every temporary determination. On the titanium trabecular group, a progressive increase of the density was seen until the fourth month of implantation. 
Our results were better than the ones obtained on the literature, with other authors obtaining a recovery of $75 \%$ of the radius cortical density in rabbits after 12 months [45-47].

After 6 months of follow up, the implants by bone were almost complete.

Several authors $[37,38,48]$ explained that bone remodelation and healing on animals is not representative for human bone growth, so when we want to extrapolate the results of animal bone regeneration to humans, we need to know that in humans, reaching osseointegration is longer.

Titanium trabecular porous structure is useful to achieve critical bone defect regeneration, or to be used as a scaffold to osteogenic cells or growth factor. Porous titanium has enough mechanical resistance to be used under bearing conditions instead of ceramics, which are very osteogenic but less resistant under loads.

Trying to compare the results of titanium trabecular with other porous metals is complicated. Published studies do not show all the studied values, and sometimes do not support their conclusions. We performed a study where implants of each porous material probed on the same animal species, same bone, same size defect and same size and morphology of the implant to evaluate the osseointegration during 9-12 months of follow up, which will be very useful and clear.

\section{Conclusions}

Trabecular titanium tolerates big plastic deformities when it is under compression forces, and can be deformed by $50 \%$ without macroscopic cracks appearing, so it can be used as a stabilized and internal fixation material between the bone defect extremes. Titanium trabecular reaches a good osseointegration after 4 months of implantation. The progression of normal bone on and inside the porous surface is real and measurable. Trabecular titanium has osseoinductive, osseoconductive and osseointegration properties, and it can be used to regenerate critical bone defects.

Author Contributions: Conceptualization, A.I.T.P. and M.F.F.; methodology, Á.A.T.P. and J.G.M.; validation, M.F.F.; formal analysis, A.I.T.P.; investigation, J.G.M., A.I.T.P., M.F.F. and Á.A.T.P.; resources, A.I.T.P.; data curation, A.I.T.P.; writing—original draft preparation, A.I.T.P. and J.G.M.; writing-review and editing, A.I.T.P. and J.G.M.; supervision, M.F.F.; project administration, M.F.F. and A.I.T.P.; and funding acquisition, J.G.M. All authors have read and agreed to the published version of the manuscript.

Funding: This research was funded by Spanish Government and European Union FEDER by the concession of the grant RTI2018-098075-B-C22.

Institutional Review Board Statement: This article does not contain any studies with human participants. The in-vivo study was conducted in accordance with the Declaration of Helsinki, and approved by the Faculty of Veterinary Sciences of the University Autonoma de Barcelona (Spain) with reference UAB-CEA AH2016.

Informed Consent Statement: Not applicable.

Data Availability Statement: The data presented in this study are available on request from the corresponding author. The data are not publicly available due to some confidential results.

Conflicts of Interest: The authors declare no conflict of interest.

\section{References}

1. Fujibayashi, S.; Neo, M.; Kim, H.M.; Kokubo, T.; Nakamura, T. Osteoinduction of bioactive titanium metal. In Key Engineering Materials; Trans Tech Publications Ltd.: Freienbach, Switzerland, 2004; Volume 254, pp. 953-956.

2. Cheng, X.Y.Y.; Li, S.J.J.; Murr, L.E.E. Compression deformation behavior of Ti-6Al-4V alloy with cellular structures fabricatedby electron beam melting. J. Mech. Behav. Biomed. Mater. 2012, 16, 153-162. [CrossRef] [PubMed]

3. Spoerke, E.D.; Murray, N.G.; Li, H.; Brinson, L.C.; Dunand, D.C.; Stupp, S.I. A bioactive titanium foam scaffold for bone repair. Acta Biomater. 2005, 1, 523-533. [CrossRef]

4. Wang, X.; Xu, S.; Zhou, S.; Xu, W.; Leary, M.; Choong, P.; Qian, M.; Brandt, M.; Xie, Y.M. Topological design and additive manufacturing of porous metals for bone scaffolds and orthopaedic implants: A review. Biomaterials 2016, 83, $127-141$. 
5. Abate, K.M.; Nazir, A.; Jeng, J.-Y. Design, optimization, and selective laser melting of vin tiles cellular structure-based hip implant. Int. J. Adv. Manuf. Technol. 2021, 112, 2037-2050. [CrossRef]

6. Pałka, K.; Pokrowiecki, R. Porous Titanium Implants: A Review. Adv. Eng. Mater. 2018, 20, 1700648. [CrossRef]

7. Dabrowski, B.; Swieszkowski, W.; Godlinski, D.; Kurzydlowski, K.J. Highly porous titanium scaffolds for orthopaedic applications. J. Biomed. Mater. Res. 2010, 95, 53-61. [CrossRef] [PubMed]

8. Bobyn, J.D.; Pilliar, R.M.; Cameron, H.U.; Weatherly, G.C. The optimum pore size for the fixation of porous surfaced metal im-plants by the ingrowth of bone. Clin. Orthop. Relat. Res. 1980, 150, 263-270. [CrossRef]

9. Beaupré, G.S.; Orr, T.E.; Carter, D.R. An approach for time-dependent bone modeling and remodeling-Theoretical development. J. Orthop. Res. 1990, 8, 651-661. [CrossRef]

10. Abate, K.M.; Nazir, A.; Chen, J.-E.; Jeng, J.-Y. Design, Optimization, and Evaluation of Additively Manufactured Vintiles Cellular Structure for Acetabular Cup Implant. Processes 2020, 8, 25. [CrossRef]

11. Caparros, C.; Guillem-Martí, J.; Punset, M.; Molmeneu, M.; Calero, J.; Gil, F.J. Mechanical properties and in vitro biological response to porous titanium alloys for intervertebrae implants. J. Mech. Behav. Biomed. Mater. 2014, 39, 79-86. [CrossRef]

12. Caparrós, C.; Ortiz-Hernandez, M.; Molmeneu, M.; Punset, M.; Calero, J.A.; Aparicio, C.; Fernández-Fairén, M.; Pérez, R.A.; Gil, F.J. Bioactive macroporous titanium implants highly interconnected. J. Mater. Sci. Mater. Med. 2016, 27, 151. [CrossRef]

13. Ortiz-Hernandez, M.; Rappe, K.S.; Molmeneu, M.; Mas-Moruno, C.; Guillem-Marti, J.; Punset, M.; Caparros, C.; Calero, J.; Franch, J.; Fernandez-Fairen, M.; et al. Two Different Strategies to Enhance Osseointegration in Porous Titanium: Inorganic Thermo-Chemical Treatment Versus Organic Coating by Peptide Adsorption. Int. J. Mol. Sci. 2018, 19, 2574. [CrossRef] [PubMed]

14. Rodriguez-Contreras, A.; Punset, M.; Calero, J.A.; Gil, F.J.; Ruperez, E.; Manero, J.M. Powder metallurgy with space holder for porous titanium implants: A review. J. Mater. Sci. Technol. 2021, 76, 129-149. [CrossRef]

15. Jafari, M.S.; Bender, B.; Coyle, C.; Parvizi, J.; Sharkey, P.F.; Hozack, W.J. Do Tantalum and Titanium Cups Show Similar Results in Revision Hip Arthroplasty? Clin. Orthop. Relat. Res. 2010, 468, 459-465. [CrossRef] [PubMed]

16. Reikeras, O.; Gunderson, R.B. Failure of HA coating on a grit-blasted acetabular cup: 155 patients followed for 7-10 years Acta Orthop. Scand. 2002, 73, 104-108. [CrossRef]

17. Rodriguez, J.A. Acetabular fixation options: Notes from the otherside. J. Arthroplast. 2006, 21, 93-96. [CrossRef] [PubMed]

18. Siegmeth, A.; Duncan, C.P.; Masri, B.A.; Kim, W.Y.; Garbuz, D.S. Modular tantalum augments for acetabular defects in revision hiparthroplasty. Clin. Orthop. Relat. Res. 2009, 467, 199-205. [CrossRef]

19. Rupérez, E.; Manero, J.M.; Ricciardi, K.; Li, Y.; Aparicio, C.; Gil, F.J. Development of tantalum scaffold for orthopaedic applications produced by space-holder method. Mater. Des. 2015, 83, 112-119. [CrossRef]

20. Nazir, A.; Abate, K.M.; Kumar, A.; Jeng, J.-Y. A state-of-the-art review on types, design, optimization, and additive manufacturing of cellular structures. Int. J. Adv. Manuf. Technol. 2019, 104, 3489-3510. [CrossRef]

21. IUPAC. Manual os Symbols and Terminology, Appendix 2, Pt. 1, Colloid and Surface Chemistry. Pure Appl. Chem. 1972, 31, 578.

22. St Pierre, J.P.; Gauthier, M.; Lefebvre, L.P.; Tabrizian, M. Three-dimensional growth of differentiating MC3T3-El pre-osteoblast on porous titanium scaffolds. Biomaterials 2005, 26, 7319-7328. [CrossRef] [PubMed]

23. Wen, C.E.; Yamada, Y.; Shimojima, K.; Chino, Y.; Asahina, T.; Mabuchi, M. Processing and mechanical properties of autogenous titanium implant materials. J. Mater. Sci. Mater. Med. 2002, 13, 397-401. [CrossRef] [PubMed]

24. Habibovic, L.J.P.; Van den Doel, P.; Wilson, M.F.; De Wijn, C.E.; Van Blitterswijk, C.A. Bone ingrowth in porous titanium implants produced by 3D fiber deposition. Biomaterials 2007, 28, 2810-2820.

25. Li, J.P.; de Wijn, J.R.; Van Blitterswijk, C.A.; De Groot, K. Porous Ti6Al4Vscaffolds directly fabricated by 3D fibre deposition technique: Effect of nozzle diameter. J. Mater. Sci. Mater. Med. 2005, 16, 1159-1163. [CrossRef]

26. Pamula, E.; Bacakova, L.; Filova, E.; Buczynska, J.; Dobrzynski, P.; Noskova, L.; Grausova, L. The influence of pore size on colonization of poly (l-lactide glycolide) scaffolds with human osteoblast like MG 63 cells in vitro. J. Mater. Sci. Mater. Med. 2008, 19, 425-435. [CrossRef] [PubMed]

27. Sicchieri, L.G.; Crippa, G.E.; de Oliveira, P.T.; Beloti, M.M.; Rosa, A.L. Pore size regulates cell and tissue interactions with PLGA-CaP scaffolds used for bone engineering. J. Tissue Eng. Regen. Med. 2012, 6, 155-162. [CrossRef] [PubMed]

28. Rappe, K.S.; Ortiz-Hernandez, M.; Punset, M.; Molmeneu, M.; Barba, A.; Mas-Moruno, C.; Guillem-Marti, J.; Caparrós, C.; Rupérez, E.; Calero, J.; et al. On-Growth and In-Growth Osseointegration Enhancement in PM Porous Ti-Scaffolds by Two Different Bioactivation Strategies: Alkali Thermochemical Treatment and RGD Peptide Coating. Int. J. Mol. Sci. 2022, $23,1750$. [CrossRef]

29. Teixeira, L.N.; Crippa, G.E.; Lefebvre, L.P.; De Oliveira, P.T.; Rosa, A.L.; Beloti, M.M. The influence of pore size on osteoblast phenotype expression in cultures grown on porous titanium. Int. J. Oral Maxillofac. Surg. 2012, 41, 1097-1101. [CrossRef]

30. Fujibayashi, S.; Neo, M.; Kim, H.M.; Kokubo, T.; Nakamura, T. Osteoinduction of porous bioactive titanium metal. Biomaterials 2004, 25, 443-450. [CrossRef]

31. Tamai, N.; Myoui, A.; Tomita, T.; Nakase, T.; Tanaka, J.; Ochi, T.; Yoshikawa, H. Novel hydroxyapatite ceramics with an interconnective porous structure exhibit superior osteoconduction in vivo. J. Biomed. Mater. Res. 2002, 59, 110-117. [CrossRef]

32. Flatley, T.J.; Lynch, K.L.; Benson, M. Tissue response to implants of calcium phosphate ceramic in the rabbit spine. Clin. Orthop. 1983, 179, 246-252. [CrossRef]

33. Hulbert, S.F.; Morrison, S.J.; Klawitter, J.J. Tissue reaction to three ceramics of porous and non-porous structures. J. Biomed. Mater. Res. 1972, 6, 347-374. [CrossRef] 
34. Brånemark, R.; Öhrnell, L.O.; Nilsson, P.; Thomsen, P. Biomechanical characterization of osseointegration during healing an experimental in vivo study in the rato. Biomaterials 1997, 18, 969-978. [CrossRef]

35. Dhert, W.J.A.; Thomsen, P.; Blomgren, A.K.; Esposito, M.; Ericson, L.E.; Verbout, A.J. Integration os press-fit implants in cortical bone: A study on interface kinetics. J. Biomed. Mater. Res. 1998, 41, 574-583. [CrossRef]

36. Hanawa, T.; Kamiura, Y.; Yamamoto, S. Early bone formation around calcium-ion implanted titanium inserted into rat tibia. J. Biomed. Mater. Res. 1997, 36, 131-136. [CrossRef]

37. Cole, B.J.; Bostrom, M.P.; Pritchard, T.L.; Sumner, D.R.; Tomin, E.; Lane, J.M.; Weiland, A.J. Use of bone morphogenetic protein 2 on ectopic porous coated implants in the rat. Clin. Orthop. 1997, 345, 219-228. [CrossRef]

38. Vehof, J.W.M.; Spauwen, P.H.M.; Jansen, J.A. Bone formation in calcium-phosphate-coated titanium mesh. Biomaterials 2000, 21, 2003-2009. [CrossRef]

39. Ferretti, C.; Ripamonti, U. Human segmental mandibular defects treated with naturally derived bone morphogenetic proteins. J. Craniofac. Surg. 2002, 13, 434-444. [CrossRef]

40. Hoyos-Nogues, M.; Velasco, E.; Ginebra, M.P.; Manero, J.M.; Gil, J.; Mas-Moruno, C. Regenerating bone via multifunctional coatings: The blending of cell integration and bacterial inhibition properties on the surface of biomaterials. ACS Appl. Mater. Interfaces 2017, 9, 21618-21630. [CrossRef] [PubMed]

41. Yuan, H.; de Bruijn, J.D.; Li, Y.; Feng, J.; Yang, Z.; de Groot, K.; Zhang, X. Bone formation induced by calcium phosphate ceramics in soft tissue of dogs: A comparative study between porous a-TCP and B-TCP. J. Mater. Sci. Mater. Med. 2001, 12, 7-13. [CrossRef]

42. Zhang, X. The osteoinductivity of Ca-P biomaterials and the potential in clinic. In Proceedings of the Asian BioCeramics, Gyeongju, Korea, 24-26 October 2002; pp. 21-24.

43. Meinig, R.P. Polylactide membranes in the treatment of segmental diaphyseal defects: Animal model experiments in the rabbit radius, sheep tibia, Yucatan minipig radius, and goat tibia. Injury 2002, 33 (Suppl. 2), B58-B65. [CrossRef]

44. Mosheiff, R.; Friedman, A.; Friedman, M.; Liebergall, M. Quantification of guided regeneration of weight-bearing bones. Orthopedics 2003, 26, 789-794. [CrossRef] [PubMed]

45. Giardino, R.; Fini, M.; Aldini, N.N.; Giavaresi, G.; Rocca, M.; Martini, L.; Zaffe, D.; Canè, V. A reabsorbable tubular chamber for the treatment of large diaphyseal bone defects. Experimental study in rabbits. Int. J. Artif. Organs 1998, 21, 473-482.

46. Nyman, R.; Magnusson, M.; Sennerby, L.; Nyman, S.; Lundgren, D. Membrane-guided bone regeneration. Segmental radius defects studied in the rabbit. Acta Orthop. Scand. 1995, 66, 169-173. [CrossRef] [PubMed]

47. Roberts, W.; Smith, R.K.; Zilberman, Y.; Mozsary, P.G.; Smith, R.S. Osseous adaptation to continuous loading of rigid endosseous implants. Am. J. Orthod. 1984, 86, 95-111. [CrossRef]

48. Bobyn, J.D.; Pilliar, R.M.; Cameron, H.U.; Weatherly, G.C. Osteogenic phenomena across endosteal bone-implant spaces with porous-surfaced intramedullary implants. Acta Orthop. Scand. 1981, 52, 145-153. [CrossRef] 